\title{
Multiple Intelligences: Language Learning and Teaching
}

\author{
Ali Derakhshan ${ }^{1} \&$ Maryam Faribi ${ }^{2}$ \\ ${ }^{1}$ Department of English Language and Literature, Golestan University, Gorgan, Iran \\ ${ }^{2}$ Department of English Language Teaching, Gorgan Branch, Islamic Azad University, Gorgan, Iran; \\ Department of English Language Teaching, Golestan Science and Research Branch, Islamic Azad University, \\ Gorgan, Iran \\ Correspondence: Ali Derakhshan, Department of English Language and Literature, Golestan University, Gorgan, \\ Iran. E-mail: a.derakhshan@gu.ac.ir
}

Received: May 8, 2015 Accepted: June 27, 2015 Online Published: July 30, 2015

doi:10.5539/ijel.v5n4p63 URL: http://dx.doi.org/10.5539/ijel.v5n4p63

\begin{abstract}
During the last three decades, multiple intelligence (MI), proposed by Gardner (1983), has drawn considerable attention from the researchers. The present study reviews the effects of Multiple Intelligences (MI) on Learning English as a Foreign Language (LEFL) and the relationship between multiple Intelligences and Teaching English as a Foreign Language (TEFL). According to Gardner's (2001) classification, nine different types of intelligences are considered important each of which has an impact on the specific skill in language learning. This paper compares and contracts the findings of different MI studies on learning and teaching, concluding that the relationship between MI, LEFL and TEFL is controversial.
\end{abstract}

Keywords: Multiple Intelligence (MI), Learning English as a Foreign Language (LEFL), Teaching English as a Foreign Language (TEFL)

\section{Introduction}

The aim of this study is to report the effects of multiple intelligences (MI) on learning and teaching English. It is assumed that there is a positive relationship between MI and learning English. For the first time, it was Gardner(1983)who proposed Multiple Intelligence Theory (MIT) and challenged the too narrowly defined intelligence with his proposal of basic human intelligence types (linguistic, mathematical, musical, spatial, bodily-kinesthetic interpersonal and intrapersonal). At the beginning, there were seven types of intelligences and by his further research, he proposed the eighth intelligence, "naturalistic intelligence", which has been added to the list and now there is the possibility of the ninth intelligence "emotional intelligence" (Armstrong, 2008).

Gardner (1983) described different types of intelligences as follows:

1. Linguistic intelligence

2. Logical-mathematical intelligence

3. Musical intelligence

4. Spatial intelligence

5. Bodily-kinesthetic intelligence

6. Naturalistic intelligence

7. Interpersonal intelligence

8. Intrapersonal intelligence

Based on Gardner's (2001) Theory, there are nine different intelligences each of which has an effect on some type of learning or teaching.

"Multiple intelligences consist of three domains: the analytical, introspective and interactive domains, these three domains serve as an organizer for understanding the relationship of the intelligences and how the intelligences work with one another" (McKenzie, 2002, p. 156).

The name of these three branches and sub branches are: 
1.1 The analytical domain

\subsubsection{Logical}

1.1.2 Rhythmic

1.1.3 Naturalist

1.2 The interactive domain

1.2.1 Linguistic

\subsubsection{Interpersonal}

\subsubsection{Kinesthetic}

\subsection{Introspective}

\subsubsection{Intro personal}

\subsubsection{Visual}

\subsubsection{Existential}

\begin{tabular}{lll}
\hline Analytic: & Introspective: & Interactive: \\
\hline 1. Logical & 1. Visual & 1. Kinesthetic \\
2. Rhythmic & 2. Existential & 2. Interpersonal \\
3. Naturalist & 3. Intrapersonal & 3. Linguistic \\
\hline
\end{tabular}

It is important for us as teachers to understand and recognize MIT and apply MI in our classes; therefore, teaching methodology will make changes and students' performance will improve to a greater extent.

\section{Review of the Literature}

Multiple intelligence Theory (MIT) was developed in 1983 by Gardner (Ahmed, 2012). The theory of MIs has always been a controversial view in language learning, and there have been many different views about the relationship between MIs and language learning (Zarei \& Mohseni, 2012). At the early genesis of MIT by Gardner (1983), the father of MI theory, his definition of intelligence was the natural ability to solve problems or create products that are valued within one or more settings; however, recently, Gardner pruned and extended his first conception of intelligence and refined it as a psychological potential that provides a learner with an opportunity to process information which can be activated in a cultural products that are culturally valuable (Zarei \& Mohseni, 2012).

Gardner's (1985) theory presents different intelligence capacities that result in many different ways of knowing, understanding, and learning about our world. Gardner's MI theory states an alternative definition of intelligence based on a radically different view of the mind. He proposes a pluralistic view of the mind, recognizing many different and discrete facets of cognition and acknowledging that people have different cognitive strengths and contrasting cognitive styles. This view of intelligence states that some finite set of mental processes gives rise to a full range of intelligent human activities. This intelligence is most completely realized in the process of solving problems and fashioning products in real-life situations (Christison, 1998).

\subsection{The Eight Kinds of Intelligences}

1) Linguistics: The capacity of using a word effectively whether orally or in writing. This intelligence includes the ability to manipulate the syntax or structure of a language, the semantic or meaning of a language, and the pragmatic or practical use of a language.

2) Logical-Mathematical: The capacity of using numbers effectively. This intelligence includes sensitivity to logic patterns and relationship.

3) Spatial: The ability to perceive the visual-spatial word accurately. This intelligence involves sensitive to color, line, shape, form, space, and the relationship that exist between these elements.

4) Bodily -Kinesthetic: Expertise in using one's whole body to express idea and feeling and facility in using one's hands to produce or transform things.

5) Musical: The capacity to perceive, transform, and express musical forms. 
6) Interpersonal: The ability to perceive and make distinctions in the moods, intentions, motivations, and feeling of other people.

7) Intrapersonal: self-knowledge and the ability to act adaptively on the basic of that knowledge .This intelligence includes having an accurate picture of oneself, awareness of inner mood, intentions, motivations, temperament, and desires.

8) Naturalist: Recognize and classify of the numerous species of an individual's environment (Armstrong, 2008, pp. 6-7).

Imagine there are two boys who want to progress their musical intelligence. The first person goes to the music store and buys several of his favorite cassettes. He takes them home, listens to them, and then tries to play what he hears. The second person goes to the music store and buys sheet music. He takes the selections home, studies and reads the music, and then sits down to play. Both of these individuals are working to develop their musical intelligence, but they do it in different ways. The preferred learning style for music for the first person is auditory; the preferred learning style for music for the second person is visual. The preferred style may differ from task to task (Christison, 1998).

MI theory is framed in light of the biological origins. In order to arrive at the list of eight intelligences, Gardner consulted evidence from several different sources. He wanted to make a clear distinction between intelligence with its biological sources and a talent or skill. He was being provocative in his choice of words. He identified the following basic criteria that each intelligence must meet to be considered intelligence.

Exceptional individuals. In some people, we can see intelligences operating at high levels. Some individuals can calculate multidigit numbers in their heads or can play a musical composition after hearing it only once. Savants are people who demonstrate amazing abilities in one intelligence while other intelligences are very low

Developmental history. Each intelligence has its own developmental history-its time of arising in childhood, its time of peaking during one's lifetime, and its time of gradual decline. Musical intelligence, for example, peaks early, but linguistic intelligence can peak very late.

Evolutionary history. Each intelligence has roots in the evolutionary history of man. For example, archaeological evidence supports the presence of early musical instruments. The cave drawings of Lascaux are good examples of spatial intelligence.

Psychometric findings. We can look at many existing standardized tests for support of the theory of multiple intelligences. The Weschsler Intelligence Scale for Children includes subtests that focus on several of the different intelligences.

Psychological tasks. We can look at psychological studies and witness intelligences working separately. For example, subjects may master a specific skill, such as solving arithmetic problems, but they may still not be able to read well. Also, individuals may have a superior memory for words but not for faces. The tasks seem to be independent from each other.

Core operations. Each intelligence has a set of core operations. For example, with musical intelligence, a person needs to be able to discriminate rhythmic structures and be sensitive to pitch.

Symbol system. Intelligences are susceptible to being symbolized. For example, there are spoken and written languages, graphic languages, computer languages, musical notation systems, and ideographic languages (Christison, 1998).

\subsection{Key Points in Multiple Intelligence Theory}

Beyond the description of the eight intelligences and their theoretical underpinnings, certain points of the MI model are important to bear in mind. Armstrong (2008) mentions the four key points that educators should pay attention to:

1) Each person possesses all eight intelligences: some people have high level of functioning in all or most of the eight intelligences.

2) Intelligences can be developed: Gardner (1983) suggests that everyone has the capacity to develop all eight intelligences to a reasonably high level of performance.

3) Intelligences work together in a complex way: intelligences are always interacting with each other.

4) There are many different ways to be intelligent: There is no standard attributes that one must have in order to be considered intelligent. Someone who is awkward at sport does not mean that she/he cannot be a marvel in building construction (Armstrong, 2008, pp. 15-16). 
Each person possesses all eight intelligences. Most people can develop intelligences to an adequate level of competency. Intelligences usually work together in a complex way. There are many ways to be intelligent within each category (Armstrong, 2008, pp. 15-16).

All human beings possess all different intelligences in varying degrees and each individual manifests varying levels of these different intelligences and thus each person has a unique "cognitive profile"; that is, a) all human possess all different intelligences in varying amounts; b) Each individual has a different composition; c) Different intelligences are located in different areas of the brain and can either working dependently or together; d) By applying Multiple Intelligences we can improve education; and e) These intelligences may define human species. (Razmjoo, 2008, p. 156)

\subsection{Assessing Instruments in Multiple Intelligence Theory}

"There is no test on the market that can provide a comprehension survey of your students' multiple intelligences. The single best tool for testing students' multiple intelligences, however, is probably one readily available to all of us is observation" (Armstrong, 2008).

Gardner (2008) believes that the classical short-answer examination is of little use. Instead, Gardner is interested in asking people to do things and to observe their skill level in the task under construction.

\subsection{The MI Teacher}

A teacher in an MI classroom differs sharply from a teacher in the traditional classroom. In the traditional classroom, the teachers, while standing at the front of the classroom, write on the blackboard, ask students questions about the assigned reading, and wait while students finish their written work. Whereas in the MI classroom, while keeping their educational objective firmly in mind, the teachers continually shift their method of presentation from linguistic to spatial to musical and so on, often combining intelligences in creative ways (Armstrong, 2008). Whether you are a traditional teacher or an MI teacher, educational programs are expected to meet numerous ends. In line with these expectations, it was put forth that students as individuals do not only respond to the stimuli in the world; they possess minds in turn hold pictures, languages, ideas, and so on (Armstrong, 2009).

Integrating MI theory in TEFL teacher education programs: EFL teacher educators are responsible for creating curricula for the programs that provide prospective EFL teachers with a foundation for what they should know as professional language teachers. Much of what we include in TEFL programs is based on academic tradition. EFL teachers are expected to know about methods, testing, theory, teaching grammar, reading, speaking, listening, and so forth. Most teacher education programs include courses in all of these subject areas. Teacher education programs are also expected to keep current by introducing teachers to the newest and most creative ideas in second language pedagogy. When new concepts and ideas are embraced by the profession, teacher education programs are challenged with integrating them into existing programs (Christison, 1998).

\subsection{The Effects of MI on Learning English}

\subsubsection{Multiple Intelligence Theory and Foreign Language Learning}

It is shown that there is a relationship between MI and foreign language learning.

exceptional foreign language learners those that in relatively short period of time (about three years) become fluent speakers, and exhibit a highly developed memory ability that is to say, how they are good at assimilating large quantities of news material and at retrieving it while interacting. In this research we are briefly consider how the verbal linguistic intelligence involved in foreign/second language learning can be supported by the other intelligence frame work. (Morgan \& Fonseca, 2004, p. 124)

\subsubsection{The Musical Rhythmic Frame}

The use of music in the language classroom is not new. In suggestopedia, for example, the teacher turns her voice to the classical music during the session (Morgan \&Fonseca, 2004).The results of current study show that musical class change the level of learning; students understand better in these methods, so musical intelligence has an effect on learning English (Morgan \& Fonseca, 2004).

The ability to sense rhythm, pitch, and melody. This includes such skills as the ability to recognize simple songs and to vary speed, tempo, and rhythm in simple melodies. You can help students develop musical intelligence by using tape recorders for listening, singing along, and learning new songs (Christison, 1998). 


\subsubsection{The Visual-Spatial Frame}

Our visual-spatial intelligence is the ability we have to perceive all the elements: Form, Shape, Line, Space, and Color (Morgan\& Fonseca, 2004). Many students understand that visual teaching aids such as charts, Pictures, Drawing, Slides, Posters, and video help to learning English better (Morgan \& Fonseca, 2004).

The ability to sense form, space, color, line, and shape. It includes the ability to graphically represent visual or spatial ideas. You can help students develop spatial/visual intelligence by providing many opportunities for visual mapping activities and encouraging students to vary the arrangements of materials in space, such as by creating charts and bulletin boards (Christison, 1998).

\subsubsection{The Logical-Mathematical Frame}

In the second language classroom problem-solving tasks are useful as learners focus mainly on meaning, but through constant rereading of a text to solve the problem, they acquire a familiarity with the vocabulary and structures used (Morgan\& Fonseca, 2004).

The ability to use numbers effectively and reason well. This includes such skills as understanding the basic properties of numbers and principles of cause and effect, as well as the ability to predict, using simple machines. You can help students develop logical-mathematical intelligence by providing manipulatives for experimentation with numbers and by using simple machines or computer programs to help children think about cause and effect (Christison, 1998).

\subsubsection{The Bodily-Kinesthetic Frame}

It is a different type of playing, drama; games and other activities that are related to the body intelligence. The gesture that we use in teaching is a kind of bodily intelligences. The use of video-club improves comprehension skills; it means by using videos, that is pictorial; students can understand the lesson and imagine the situation better so they can concentrate more in it.

The ability to use the body to express the ideas and feelings and to solve the problems. This includes such physical skills as coordination, flexibility, speed, and balance. You can help your students develop their bodily-kinesthetic intelligence by providing opportunities for physical challenges during the second/foreign language lesson (Christison, 1998).

\subsubsection{The Interpersonal Frame}

Working as group and being cooperative in learning are kinds of interpersonal frames. By using this kind of intelligence we improve listening and speaking task.

The ability to understand another person's moods, feelings, motivations, and intentions. This includes such skills as responding effectively to other people in some pragmatic way, such as getting students or colleagues to participate in a project. As an EFL teacher you can help students develop interpersonal intelligence through activities that involve them in solving problems and resolving conflict (Christison, 1998).

\subsubsection{The Intrapersonal Frame}

The intrapersonal intelligence helps us to understand the internal aspects of the self and to practice self discipline. It can be related to studies about meta-cognitive knowledge and language learning, where meta-cognitive refers to knowledge about oneself, about the language, about procedures or to be used for certain type of tasks (Wendenas, as cited in Morgan \& Fonseca, 2004, p. 123).

The ability to understand yourself-your strengths, weaknesses, moods, desires, and intentions. This includes such skills as understanding how you are similar to or different from others, reminding yourself to do something, knowing about yourself as a language learner, and knowing how to handle your feelings, such as what to do and how to behave when you are angry or sad. You can help EFL students develop intrapersonal intelligence by letting them express their own preferences and help them understand their own styles of learning (Christison, 1998).

\subsubsection{The Naturalist Frame}

All things related to nature can improve speaking and writing skills for example explaining more about writing map, natural words or writing a paragraph about their country and their city.

The ability to recognize and classify plants, minerals, and animals, including rocks and grass, and all variety of flora and fauna. It is also the ability to recognize cultural artifacts like cars or sneakers. You can help your students develop their naturalist intelligence by focusing their attention on the world outside the classroom (Christison, 1998). 


\subsubsection{The Effect of MI-Based Reading Task}

Modirkamene and Bagherian (2012) found out that personal differences have been more effective than educational program.

Instruction congruous with various scopes of learning motives could extensively establish a sense of belonging, motivation, competence and enjoyment for the learners. To this end, the significant aim of the researchers on individual differences was to foresee which learners would succeed in the learning. (Kirby \&McDonald, as cited in Modirkhamene \& Bagherian, 2012, p. 1013)

A look at the literature review shows that a number of MI studies were carried out in the realm of EFL and other languages. For example, Hajhashemi (2011) investigated the relationship between EFL learners multiple intelligence profiles and their language learning strategies. He selected 229 EFL students from differing grades and identified their intelligences and language learning strategies by the questionnaires. The findings manifested a significant but low correlation between MI and language learning strategies. All eight types of intelligences, verbal - linguistic, visual - spatial, and logical mathematical intelligences indicated meaningful relation with nearly all strategies (Modirkhamene \& Bagherian, 2012).

The results obtained from the whole research were as follow: there is a significant relationship between MI and speaking skill. Therefore, it is concluded that the speaking skill can be improved if an individual's MIs is recognized.

Armstrong (2008) has synthesized these ideas into four key points that educators find attractive

1. Each person possesses all eight intelligences. In each person the eight intelligences function together in unique ways. Some people have high levels of functioning in all or most of the eight intelligences; a few people lack most of the rudimentary aspects of intelligence. Most people are somewhere in the middle, with a few intelligences highly developed, most modestly developed, and one or two underdeveloped.

2. Intelligences can be developed. Gardner suggests that everyone has the capacity to develop all eight intelligences to a reasonably high level of performance with appropriate encouragement, enrichment, and instruction.

3. Intelligences work together in complex ways. No intelligence really exists by itself in life. Intelligences are always interacting with each other. For example, to cook a meal, one must read a recipe (linguistic), perhaps double it (logical-mathematical), and prepare a menu that satisfies others you may cook for (interpersonal) and yourself (intrapersonal).

4. There are many different ways to be intelligent. There is no standard set of attributes that one must have in order to be considered intelligent. I remember a friend in high school who was completely awkward in the dance class and yet a marvel in building construction. Both activities required bodily- kinesthetic intelligence (Christison, 1998).

\subsubsection{The Effects of MI in Writing}

"For ESL/EFL learners, mastery of writing ability is counted as one of the contributing avenues to success in learning the language" (Sadeghi \& Farzizadeh, 2012, p. 137); however, writing is a basic communication skill and a conceptualization which unique asset in the process of learning a second language. In his opinion writing is an act of involves thinking, writing, and thinking during the process (Sadeghi \& Farzizadeh, 2012)

Writing is one of the most challenging skills for L2learners to master and the important roles that one's multiple intelligence can play begin to evolve when we look at how the brain sets out to experience the actual work of reading and writing (Armstrong, as cited in Sadeghi \& Farzinzadeh, 2012)

Sadeghi and Farzinzadeh (2012) believe that developing the writing ability is a skill which is given slight attention in Iranian contexts both by teachers and learners. A small amount of class time is allocated to developing this skill. Writings are mostly done outside the classroom for which the students seek help from other sources. It is often seen as a means of strengthening vocabulary or grammatical knowledge rather than as a tool for communicating ideas. However, students can ideally benefit from their individual potentials in intelligences to draw on during the act of writing, an attempt writing, an attempt the highlighting of which will bring about valuable benefits. With an eye always on the students' intelligences, a lot can hopefully be done to meet different needs of different students in different settings. Teachers can have other choices available when teaching in addition to that of overemphasizing IQ as the only factor important in learning, and thus this will create a sense 
of equality by focusing on all individuals possessing whatever intelligence type they might and not only on those who have high IQs.

In an effort to understand learner-centered instruction from the perspective of multiple intelligences (MI), Saricaoglu and Arikan (2009) suggest that the purpose of second teacher action was to investigate the use of MI theory in shaping and informing instructional strategies, curricula development, and alternative forms of assessment with second language learners. Researchers' premise was that given what we know about the educational needs of second language learners, all teachers must be better equipped to widen their pedagogical repertoire to accommodate linguistically, culturally, and cognitively diverse students. The results indicated that students did achieve greater success rates when the MI theory was implemented (Haley, 2004).Moreover, Researchers has investigated the relationship between gender and MI of specific learners. With an aim of finding out whether or not there were any gender differences in students' intelligence profiles in relation to their gender.

Alternatively, Loori conducted a study on 90 English language learners and found that males showed higher preference in logical/mathematic while females showed higher preference in logical/mathematical intelligence (Saricaoglu \& Arikan, 2009). On the other hand, Razmjoo (2008) found that the use of intrapersonal intelligence by females were higher than that of the males whereas no significant difference was found between male and female participants regarding language success and types of intelligences. Hence, contrasts exist between the results of these two studies which studied the relationship with gender and MI (Saricaoglu \& Arikan, 2009).

Borek (2003) suggested that having a MI-based classroom can be an appropriate way for students to do their best and develop their own ways of learning. To find empirical evidence for this claim, number of studies were carried out (Borek, as cited in Zarei \& Mohseni, 2012, p. 1307). For example, Buchanan and Furnham (2005) conducted a study to examine this role and concluded that women tend to provide lower estimates of general, mathematical, and spatial ability, but higher estimates of interpersonal and intrapersonal intelligence than men.(Buchanan \& Furnham, as cited in Zarei \& Mohseni, 2012, p. 1307)

Multiple intelligence theory has been proposed to consider new training methods for his purpose (Kirkas, as cited in Gurbuzoglu, 2013, p. 27)

Gardner mentioned two important advantages of multiple intelligences in his education. They are: It gives the opportunity to plan our education program so as to make the students desired. (For example, musician and scientific training) It enables us to reach more students trying to learn different disciplines and theories learning would be realized much easily on condition that students are trained by using these intelligence fields. (Bümen as cited in Gurbuzoglu, 2013, p. 28)

The greatest effect of the theory in the process of teaching is to increase the creativity of teachers in developing teaching strategies. Because, when teachers and planners think activities for each intelligence type, they inevitably enlarge their method and technique repertoire, reveal different and original techniques. As different intelligence types are used in classroom activities during that process, cooperation impossible between the teachers whose expertise areas are completely different from each other. For example, one needs to communicate and get advice of music teacher while planning an activity related to musical intelligence. (Demirel, as cited in Gurbuzoglu, 2013, p. 29)

\subsection{The effects of MI on Teaching English}

When someone teaches English discovering the MIs in himself and in his students, he can teach better and more effectively. Based on researchers' experience in teaching English as a foreign language (TEFL) field, they noticed that most students face difficulties in learning EFL in particular situations, while the same students are good at other activities in the class. Thus, MI has some implications for teachers which are as follows:

1. As a tool to help students develop understanding and appreciation of their own strengths and preferred the way of learning.

2. As a tool to develop a better understanding of learners intelligences.

3. As a guide to provide a greater variety of ways for students to learn and to demonstrate their learning.

4. As a guide to develop lesson plans that addresses the full range of learners need.

\subsubsection{The Relationship between MI and Successful Teaching}

There is much evidence confirming that schools and institutions where multiple intelligences theory is applied are effective (Gardner, as cited in Ahmed, 2012, p. 29) and with the understanding of the theory, teachers can better understand the learners. They can allow learners to discover their strengths, learn in many ways, and can 
help students to be in control of their learning (Guignon, as cited in Ahmed, 2012, p. 29).It is known that schools have emphasized reading and writing in language teaching. The multiple intelligences theory opens the door to a variety of teaching strategies which can be easily applied in the language classroom (Ahmed, 2012).

\subsubsection{The Impact of Multiple Intelligences on Developing Teachers' Speaking Skill}

Speaking skill plays a vital role in the communication process. It is the most important one among wide variety of linguistic activities. Developing speaking skill contributes to creating an effective connection among the individual's members of society. It is an active part in their daily life and a tool for learning (Dorgham, as cited in Salem, 2013).

\section{Gardner's Categories of Intelligence:}

Gardner (1983) suggested that every person has individual intelligences' profile that consists of combinations of seven different intelligence types (Razmjoo, 2008). "In 1999, Gardner added the eighth intelligence type to the list; that is, natural intelligence. Moreover, two years later, the ninth type, namely existential intelligence was added to the list". (Razmjoo, 2008, p. 158)

\subsubsection{The Effect of MI-Based Reading Task}

The results obtained from the whole research were as follow: there is a significant relationship between MI and speaking skill. Therefore, it is concluded that the speaking skill can be improved if an individual's MIs is recognized.

Armstrong (2008) has synthesized these ideas into four key points that educators find attractive

1. Each person possesses all eight intelligences. In each person the eight intelligences function together in unique ways. Some people have high levels of functioning in all or most of the eight intelligences; a few people lack most of the rudimentary aspects of intelligence. Most people are somewhere in the middle, with a few intelligences highly developed, most modestly developed, and one or two underdeveloped.

2. Intelligences can be developed. Gardner suggests that everyone has the capacity to develop all eight intelligences to a reasonably high level of performance with appropriate encouragement, enrichment, and instruction.

3. Intelligences work together in complex ways. No intelligence really exists by itself in life. Intelligences are always interacting with each other. For example, to cook a meal, one must read a recipe (linguistic), perhaps double it (logical-mathematical), and prepare a menu that satisfies others you may cook for (interpersonal) and yourself (intrapersonal).

4. There are many different ways to be intelligent. There is no standard set of attributes that one must have in order to be considered intelligent. I remember a friend in high school who was completely awkward in the dance class and yet a marvel in building construction. Both activities required bodily- kinesthetic intelligence (Christison, 1998).

\section{Conclusion}

The main purpose of this study was to review intelligence types that students employ in relation to their foreign language learning. Saricaoglu and Arikan (2009) argued that logical-mathematical intelligence was the leading intelligence type and the musical intelligence was the least common intelligence type employed by the students who participated in this study.

It can be concluded that no single method of teaching writing can best suit all types of learners since writing is shown to be differentially related to different types of intelligence and since human beings enjoy different levels of the various types of intelligence, the logical result to be drawn is that learners will experience differential success no matter how they are taught writing (Zarei \& Mohseni, 2012). Sadeghi and Farzizadeh (2012) concluded that the components of MI had a significant correlation with writing ability. In the second or foreign language classrooms, it is possible to motivate learners by different activities relating to the different intelligences. Pishghadam and Moafiun (2008) concluded that no significant differences were found between Multiple Intelligences and successful teaching. Salem's (2013) study proved the effectiveness of MI based instruction on developing speaking skill of the pre-service teachers of English language classroom.

\section{Implications and Suggestions for Further Research}

Researchers believe that multiple intelligences can be largely practical in Iran and elsewhere.

Based on the pragmatic approach, MIT should be applied in classes in order to boost up the students' learning skills. This can possibly include all other kinds of courses. The teachers have a prominent role in distinguishing 
the students' capability using MIT and consequently guide them towards success. Researchers believe that it needs lots of time to work on the effect of MI. instead; investing more in detail is highly recommended. Applying the results of the study to the class in order to increase the proficiency level of the students would probably satisfy the goal of the study.

\subsection{Implication for Teaching English as a Foreign Language}

Several steps were introduced in MI theory to teachers either in-service or pre-service program:

Step one: Introduce the basic theory;

Step two: Use the MI inventory;

Step three: Categorize familiar EFL activities;

Step four: Conduct a personal audit of teaching strategies;

Step five: Develop different assessment techniques that also address the eight intelligences (Saeidi, 2009, p. 108).

Applying multiple intelligence theory was different: It did not mean that we abandon activities that are important to us and to our students. It means that we control them and think about our students (Saeidi, 2009).

\subsection{Implications of MIT in ELT}

Results of this paper show that it is positive effective to motivate and activate students' mind regarding nine different types of intelligences and by working in some (especial) types of intelligences which activate students' mind English learning will be improved (Ibmian \& Hadban, 2013).

\section{References}

Ahmed, A. (2012). The relationship between multiple intelligences theory and methods of ELT. Journal of Learning and Teaching, 4(2), 26-41.

Armstrong, T. (2008). Multiple intelligences in the classroom. California: Alexandria.

Christison, M. (1998). Applying multiple intelligences theory. Preserves \& in-service TEFL Education programs, 36(2), 2-19.

Gardner, H. (1983). Frames of mind: The theory of the multiple intelligences. New York: Basic Book.

Gurbuzoglu, S. (2013). The effect of multiple intelligence theory based teaching on students' achievement and retention of knowledge. International Journal on new Trend in Education and Their Implication, 4(3), 27-36.

Haley, M. (2001). Understanding learner-centered instruction from the perspective of multiple intelligences. Foreign Language Annals, 34(4), 355-367. http://dx.doi.org/10.1111/j.1944-9720.2001.tb02068.x

Haley, M. (2004). Learner-centered instruction and the theory of MI with second language learners. Teacher College Record, 106(1), 163-180. http://dx.doi.org/10.1111/j.1467-9620.2004.00326.x

Ibmian, K. S., \& Hadban, A. D. (2013). Implications of multiple intelligences theory in ELT field. International Journal of Humanities and SocialScience, 3(4), 292-297.

Loori, A. (2005). Multiple intelligences: A comparative study between the preferences of male and females. Social Behavior and Personality, 33(1), 77-88. http://dx.doi.org/10.2224/sbp.2005.33.1.77

Mckenize, W. (2002). Multiple intelligences and instructional technology: A manual for every mind. Eugene, or: International society for Technology in education.

Modirkhamene, S., \& Bagherian, M. (2012). The effect of multiple intelligences - based reading task on EFL learners' reading comprehension. Theory and Practice in Language Studies, 2(5), 1013-1021. http://dx.doi.org/10.4304/tpls.2.5.1013-1021

Morgan, J., \& Fonsecu, C. (2004). Multiple intelligence theory and foreign language learning: A brain - Based perspective. International Journal of English Studies, 4(1), 119-136.

Pishghadam, R., \& Moafiun, F. (2008). The relationship between Iranian EFL teachers multiple intelligences and their successful teaching in language institutes. Quarterly Journal of HumanitiesAlzahraUniversity, 18(4), 102-127.

Razmjoo, A. (2008). On the relationship between multiple intelligences and language proficiency. The Reading Matrix, 8(2), 155-174.

Richard, J., \& Rodgers, T. (2007). Approaches and methods in language teaching. Cambridge: Cambridge. 
Saeidi, M. (2009). The implementation of multiple intelligence theory in the classroom: Different ways of learning and teaching. Journal of Teaching English as a Foreign Language and Literature, 1(1), 103-116.

Sadeghi,K., \& Farzizadeh, B. (2012). The relationship between multiple intelligence and writing ability of Iranian EFL learners. English Language Teaching, 5(11), 136-142. http://dx.doi.org/10.5539/elt.v5n11p136

Salem, A. (2013). The impact of multiple intelligences - based instruction on developing speaking skills of the pre - service teachers of English. English Language Teaching, 6(9), 53-66.

Saricaoglu, A., \& Arikan, A. (2009). A study of multiple intelligences, foreign language success and some selected variable. Journal of Theory and Practice in Education, 5(2), 110-122.

Zarei, A., \& Mohseni, F. (2012). On the relationship between multiple intelligences and grammatical and writing accuracy of Iranian learners of English. Us-China Foreign Language, 10(7), 1306-1317.

\section{Copyrights}

Copyright for this article is retained by the author(s), with first publication rights granted to the journal.

This is an open-access article distributed under the terms and conditions of the Creative Commons Attribution license (http://creativecommons.org/licenses/by/3.0/). 